\title{
Correntes teóricas da ciência da informação
}

Carlos Alberto Ávila Araújo

Doutor em ciência da informação. Professor adjunto da Escola de Ciência da Informação da Universidade Federal de Minas Gerais. E-mail: casal@eci.ufmg.br

\section{Resumo}

Neste artigo, são apresentadas seis correntes teóricas da ciência da informação: os estudos de natureza matemática (incluindo a recuperação da informação e a bibliometria), a teoria sistêmica, a teoria crítica, as teorias da representação, os estudos em comunicação científica e os estudos de usuários. É analisado o conceito de informação em cada uma destas teorias e identificado como, historicamente, tais teorias contribuíram para consolidar um paradigma positivista para o campo. Por fim, são analisadas contribuições recentes que buscam apontar limitações no conceito de informação deste paradigma e possibilidades de superação a partir de novos conceitos e ideias.

\section{Palavras-chave}

Ciência da informação. Teorias da informação. Conceito de informação.

\section{Theoretical currents in information science}

\begin{abstract}
In this article, six theoretical currents of Information Science are presented: the mathematical studies of information (including information retrieval and bibliometrics), the systemic theory, the critical theory, the theories of representation, the studies in scientific communication and the studies of users. The concept of information is analyzed concerning each one of those theories which have historically contributed to consolidate a positivist paradigm in this area. Recent contributions have been analyzed trying to point out limitations in the concept of information of this paradigm and possibilities of transcending new concepts and ideas.
\end{abstract}

\section{Keywords}

Information science. Information theories. Concept of information. 
Ao longo de seu desenvolvimento, a ciência da informação (CI) viu surgirem e se consolidarem, dentro dela, diferentes áreas e subáreas específicas. Tais campos, orientados por diversas correntes e perspectivas teóricas, acabaram por desenvolver, também, conceitos particulares de informação, algumas vezes semelhantes, outras vezes sobrepostos e, em alguns casos, discordantes.

Neste texto, apresentam-se seis dos campos que constituíram historicamente a CI, analisando-se os conceitos de informação presentes. Naturalmente, as demarcações dos campos não são absolutas e, sob outros pontos de vista, poder-se-ia apresentar a CI composta por outros itens, a partir de diferentes critérios de divisão. Busca-se aqui, contudo, tendo como eixo o conceito mesmo de informação, identificar percursos específicos (que conformariam áreas, subáreas ou mesmo correntes teóricas) a partir das problemáticas, das contribuições de outros campos e dos conceitos correlatos mobilizados por eles.

Ao final, é realizada uma correlação entre as correntes teóricas, de modo a identificar aproximações e distanciamentos e, sobretudo, perceber tendências ou traços de estabilidade e de mudança nos diferentes conceitos adotados pelas teorias. Para tanto, são utilizados argumentos e ideias de autores contemporâneos da CI que dialogam direta ou indiretamente com as correntes teóricas analisadas.

\section{TEORIA MATEMÁTICA, RECUPERAÇÃO DA INFORMAÇÃO E BIBLIOMETRIA}

É bastante comum encontrar, na área de CI, a indicação da importância da Teoria Matemática da Comunicação de Shannon e Weaver, apresentada em 1948 e publicada em 1949, como um prenúncio ou mesmo inauguradora do campo. Essa teoria é normalmente conhecida como "Teoria da informação" e tal denominação não se deu sem motivos: trata-se da teoria que pela primeira vez enunciou um conceito científico de "informação". Os autores estão preocupados com a eficácia do processo de comunicação e, para tanto, elegem como conceito central de seu trabalho a noção de informação.

Shannon e Weaver reconhecem que as questões relativas à comunicação envolvem três níveis de problemas. O primeiro trata dos problemas técnicos, relativos ao transporte físico da materialidade que compõe a informação (como, por exemplo, o volume do som numa conversa ou a qualidade da impressão em um papel). O segundo nível se refere aos problemas semânticos, isto é, se relaciona com a atribuição de significado. Enquanto o primeiro nível envolve apenas uma operação mecânica (reconhecer as letras num papel, captar os sons de uma fala), o segundo se relaciona a uma operação mental específica, a de depreender, de determinada materialidade (sonora, visual, etc), um sentido, que pode se dar de maneira conotativa ou denotativa, literal ou irônica, metafórica, etc. O terceiro nível é o pragmático, relaciona-se com a eficácia. Quem emite informações a outrem deseja, de algum modo, provocar um comportamento, causar alguma reação (convencer alguém a comprar um produto, eleger um candidato, pedir um favor, etc).

Ou seja, os autores têm clareza dos diversos níveis e complexidades envolvidos com os problemas relacionados à informação (ou à comunicação da informação). Produzem uma teoria, contudo, que está voltada apenas para o primeiro nível. Ao fazer isso, eles tornam possível a construção de um referencial teórico para os problemas relacionados com o transporte físico da informação. E é a partir dessa "brecha", dessa proposição de uma forma "científica" de estudo da informação, que se constrói o projeto de uma ciência da informação.

Ao "limpar" o conceito de suas dimensões de significação e de relação social, Shannon e Weaver descartam a subjetividade como elemento componente da informação, tornando possível uma aproximação dela enquanto um fenômeno objetivo, independente dos sujeitos que com ela se relacionam e, portanto, passível de ser estudada "cientificamente". 
Os processos que envolvem a informação passam a ser compreendidos numa lógica linear. Os autores definem a comunicação como um processo em que uma fonte, a partir de um transmissor, por meio de um canal, envia informação a um receptor, que a conduz a um destino. A informação é definida como uma medida da incerteza - não como aquilo que é informado, mas como aquilo que se poderia informar. Diante de uma pergunta com apenas duas opções de resposta, o grau de informação seria da ordem de 50\%. Diante de uma pergunta com mais opções (uma situação com maior grau de incerteza), o valor informativo aumenta. Em situações de alta previsibilidade, o grau informativo é baixíssimo.

Tal raciocínio articula diferentes conceitos importados das ciências exatas, tais como o de entropia e o de probabilidade. A informação é uma entidade da ordem da probabilidade, sendo a entropia um de seus atributos. Tais conceitos, articulados com outros presentes nesta teoria (como os de repertório, estrutura, código, ruído e redundância) dão o tom da problemática geral que a particulariza: como quantificar a informação, para determinar a quantidade ótima, com o grau adequado de redundância, prevendo a interferência do ruído e a capacidade do canal, a ser transferida de um emissor a um receptor.

Os conceitos dessa teoria têm um impacto imediato nos estudos que se seguem, em anos posteriores, a respeito da transferência de informação. São elaboradas fórmulas para prever quanto texto pode ser transmitido em cada formato, a partir do repertório de diferentes grupos, respeitando a capacidade de cada canal, entre outros aspectos.

No campo da CI, a aplicação mais decisiva se dá no campo dos estudos em recuperação da Informação. Essa área, que surge na década de 1950 e que chegou a ser entendida, algumas vezes, como sinônimo ou como o núcleo central da CI (SARACEVIC, 1996), voltou-se prioritariamente para a questão da medição de procedimentos para a recuperação da informação. Entre os conceitos centrais desse campo destacamse os de revocação e precisão, que operam na lógica da probabilidade e da entropia, na busca de um ideal de recuperação que contemple uma quantidade boa de itens (exaustividade) e, ao mesmo tempo, traga itens relevantes (especificidade).

Os estudos de Cranfield, que se estenderam ao longo da década de 1950, representam um dos exemplos mais significativos de estudos experimentais, no campo da CI, a partir do conceito de informação elaborado pela teoria matemática. Vários sistemas de representação e recuperação foram testados em termos de propriedades como revocação e precisão, para testes de comparação de eficácia destes vários sistemas.

Uma perspectiva um pouco diferente, e na verdade até anterior à Teoria Matemática, é a da bibliometria, que consiste na aplicação de técnicas estatísticas para a contagem e estabelecimento de padrões de regularidade em itens informacionais como número de livros, de edições, de autores que publicam em periódicos, entre outros. Desenvolvido por meio de leis empíricas desde a década de 1920 (Lotka, Bradford, Zipf), tal campo ganhou fôlego a partir da década de 1960, com as possibilidades de automação e com a criação do campo de estudos de análise de citação, com Garfield. Seguiram-se diversas teorias (teoria epidêmica do crescimento da literatura, teoria do acoplamento bibliográfico) e variações de campo de atuação (informetria, cientometria, webometria), todos preservando a mesma lógica: de que a informação pode ser quantificada e que, por meio dessa quantificação, seria possível prever suas manifestações futuras, já que, tal como os fenômenos da natureza, ela também obedeceria a leis que regem sua existência.

Os estudos bibliométricos não são, a rigor, estudos de transporte de informação - no que se distanciam da perspectiva da Teoria Matemática. Por outro lado, definem a informação da mesma maneira, o que se pode perceber, a partir da década de 1970, com a aproximação entre a Bibliometria e a Recuperação da Informação, tanto com a utilização de contagens de citações para a recuperação da informação como para a medição bibliométrica de itens recuperados em processos de busca e seleção.

Ci. Inf., Brasília, DF, v. 38, n. 3, p.192-204, set./dez., 2009 
A perspectiva matemática do transporte de informação continua atual, apesar das várias críticas recebidas, como se pode ver em teorizações como a de Saracevic, para quem a CI estuda "os problemas da efetiva comunicação do conhecimento" (1996, p. 47); de Buckland (1991), que conceitua a informação como "coisa"; e de Le Coadic, que confirma, após 80 anos desde a formulação da primeira lei quantitativa no âmbito da CI, "a existência, no campo da informação, de regularidades, distribuições e relações mensuráveis universais” (2007, p. 221).

\section{TEORIA SISTÊMICA}

A CI irá sentir, concomitantemente ao predomínio da lógica matemática para o conceito de informação, a influência do sucesso que a Teoria Sistêmica passa a obter, cada vez mais, nos meios científicos. Originada com Bertalanffy, na década de 1930, tal teoria ganha imensa expressão no campo da CI com a publicação do trabalho de Wiener, em 1948, sobre a cibernética.

Se a área de transmissão e recuperação da informação tem origem na lógica das ciências exatas (matemática e física), a Teoria Sistêmica da informação tem origem em princípios da biologia. A principal ideia a embasar tal visão é a de que o todo é maior do que as partes e de que as partes devem ser estudadas, necessariamente, a partir da função que desempenham para a manutenção e sobrevivência do todo. Os princípios biológicos passam a ser entendidos como uma espécie de método geral para o estudo de qualquer fenômeno. A lógica é a mesma que preside o estudo do corpo humano: cada parte, cada órgão, é inserido num sistema (respiratório, digestivo, etc) e apreendido a partir do papel que ele desempenha neste sistema - e, consequentemente, do papel que este sistema desempenha no todo, o organismo humano. O mesmo vale, por exemplo, para o estudo da água, dos seres vivos, das doenças, etc.

Enquanto o modelo físico pensava os processos numa lógica essencialmente linear, do transporte de um ponto a outro (e sobre a forma de otimizar esse transporte), a lógica sistêmica privilegia a ideia de ciclo, de circularidade: todo processo sempre

Ci. Inf., Brasília, DF, v. 38, n. 3, p.192-204, set./dez., 2009 representa a saída de alguma entidade, e essa saída vai provocar a formação de novos elementos de entrada - como normalmente expresso nos conceitos de input e output.

Em pouco tempo, tal modelo passou a fazer grande sucesso no âmbito das várias ciências, inclusive daquelas classificadas como sociais. A ciência política adotou um modelo que prevê a escolha dos líderes políticos pelo voto como o mecanismo de entrada (input) e os resultados dos trabalhos das casas executiva e legislativa como o mecanismo de saída (output), o qual irá fornecer os critérios para "alimentar" uma nova escolha (uma gestão bem avaliada será reconduzida; uma gestão vista como ruim será substituída por outra). $\mathrm{Na}$ administração, diversos modelos teóricos buscaram determinar o ambiente interno e o ambiente externo da empresa, os riscos e as oportunidades, os pontos fortes e os pontos fracos.

O modelo organísmico da teoria sistêmica articula uma série de conceitos particulares, tais como a ideia de totalidade (o conjunto, como por exemplo uma cidade, uma empresa, uma equipe), os objetos que compõem a totalidade (os membros tomados isoladamente - as pessoas, os grupos, os departamentos), os atributos destes objetos (características específicas que cada objeto tem para o desempenho adequado da sua função), os processos (a "importação" ou entrada de algo, a "exportação" ou saída, e o processamento desse algo, entendido como as tarefas necessárias para a sobrevivência do sistema) e o ambiente (aquilo que é externo à totalidade, de onde ela retira os elementos de entrada e para onde dirige os elementos de saída).

No âmbito da CI, a teoria sistêmica apresentou duas grandes manifestações. A primeira, em nível macro, relaciona-se às teorias funcionalistas a respeito da função da informação na sociedade. Vários autores dedicaram-se a mapear a importância das instituições e serviços de informação (bibliotecas, arquivos, centros de documentação, museus, etc) para a manutenção do equilíbrio da sociedade: promover a adequada socialização dos membros, garantir a preservação da memória cultural das 
gerações anteriores, conter um repositório de dados para a orientação das ações e tarefas a serem desempenhadas, servir de complemento para as atividades educacionais, entre outras (SHERA, 1970; RIVIÈRE, 1993).

A segunda grande manifestação se relaciona com o desenvolvimento das teorias sobre os sistemas de informação. Diversos estudos neste campo buscaram determinar e caracterizar os diversos processos necessários para o adequado funcionamento dos sistemas de informação. Nestes diversos estudos, os conceitos sistêmicos estão por todo o raciocínio. Os sistemas de informação são sempre pensados a partir da lógica dos processos de entrada (entrada de dados, com a aquisição de itens informacionais, a seleção destes itens para a composição de determinado acervo), de processamento (os itens informacionais que dão entrada num sistema de informação precisam ser descritos, catalogados, classificados, indexados) e de saída (pelo acesso aos itens informacionais por parte dos usuários, na forma de disseminação, entrega da informação, empréstimo, etc).

Uma das ideias dessa teoria, de que os sistemas precisam ser estáveis (isto é, devem manter uma determinada dinâmica de funcionamento com controle do que entra e do que sai), serve inclusive como sustentação para as cinco leis da biblioteconomia (RANGANATHAN, 1931), particularmente para a última delas, a de que a biblioteca é um organismo em crescimento. A necessidade de manter a "homeostase" faz com que um sistema de informação não possa ir crescendo e adquirindo novos itens informacionais ad infinitum: ele precisa promover desbastes, descartes, como forma de manter um equilíbrio e continuar cumprindo suas funções.

Outras ideias dessa teoria, como a de que as partes são interdependentes com funções específicas, está na origem do "princípio de proveniência", basilar no âmbito das teorias arquivísticas. $\mathrm{O}$ mesmo vale para a ideia sistêmica de ciclo, presente na teoria das três idades dos documentos arquivísticos (SCHELLENBERG, 1973).

\section{TEORIA CRÍTICA DA INFORMAÇÃO}

A terceira das teorias a proporcionar um conceito de informação encontra-se no âmbito das teorias críticas. Enquanto as outras teorias vistas até aqui buscam fundamentação na física e na biologia (portanto, nas ciências da natureza), as teorias críticas fundamentam-se principalmente nas humanidades particularmente na filosofia e na história.

A postura da teoria crítica se relaciona essencialmente com a ideia de suspeição de que a realidade tenha fundamento nela mesma. Ao contrário das aproximações "positivas" ao real, a teoria crítica tem por atitude epistemológica a desconfiança, a negação do evidente, a busca do que pode estar escondido ou camuflado.

Sua origem remonta à filosofia de Heráclito, para quem o fator mais relevante para a explicação da realidade humana era a mudança, e não a estabilidade, como defendia Parmênides. Tal argumento foi retomado, séculos depois, por Hegel, quando da formulação da dialética como método filosófico para a compreensão da realidade. Sua aplicação no campo das ciências humanas e sociais foi bastante vasta, sendo a mais importante delas a teoria marxista, que vinculou a abordagem dialética à compreensão dos fatos humanos e sociais. O resultado de tal empreitada é que as dimensões da tensionalidade e da historicidade se tornaram as mais relevantes para a explicação da realidade humana.

No campo da CI, é exatamente a perspectiva marxista a que mais se consolida no âmbito da teoria crítica da informação. Os modelos anteriores, principalmente o sistêmico, de natureza biológica, enfatizavam a estabilidade, a permanência (por meio da definição de leis, do estabelecimento das funções) e a integração (cada parte exercendo seu papel para a manutenção do todo). $\mathrm{Na}$ direção oposta, a teoria crítica vai enfatizar o conflito, a desigualdade, o embate de interesses em torno da questão da informação - e para tanto, buscará explicar os fenômenos a partir de sua historicidade.

Ci. Inf., Brasília, DF, v. 38, n. 3, p.192-204, set./dez., 2009 
O estudo da informação do ponto de vista dessa teoria não se atém mais às condições de eficácia de seu transporte, de suas funções para o equilíbrio social ou dos procedimentos funcionais para seu processamento no âmbito dos sistemas. A informação é entendida, pela teoria crítica, como recurso fundamental para a condição humana no mundo e, como tal, a primeira percepção que se tem é de sua desigual distribuição entre os atores sociais. Como recurso, a informação é apropriada por alguns, que garantem para si o acesso. Aos demais, sobra a realidade da exclusão.

Assim é que as temáticas estudadas no âmbito dessa teoria envolvem a questão da democratização da informação, do acesso à informação por parte de grupos e classes excluídos e marginalizados, a criação de formas e sistemas alternativos de informação, e mesmo estudos sobre a contrainformação, como forma de rejeição aos regimes informacionais hegemônicos.

Ao mesmo tempo, estudos que denunciam a dimensão ideológica dos equipamentos culturais (museus, arquivos, bibliotecas), reproduzindo lógicas sociais de dominação e aprofundando diferenças cognitivas e de sensibilidade, são conduzidas por pesquisadores que aliam o estudo da informação a uma sociologia crítica da cultura (BOURDIEU, 2007).

É principalmente nos países do Terceiro Mundo que tal corrente se desenvolve, embora exista volume considerável de contribuições de autores franceses e alemães para sua evolução teórica, e apoio institucional de órgãos como a Unesco, para o desenvolvimento de ações práticas no campo da democratização. Ao mesmo tempo, grupos hegemônicos da produção científica em CI, ligados ao contexto anglo-saxão (Inglaterra e EUA), frequentemente rejeitam e desqualificam estes estudos, recusando seu pertencimento ao campo da CI por estarem "politizando" as discussões (MAT'TELART, 2002).

Ci. Inf., Brasília, DF, v. 38, n. 3, p.192-204, set./dez., 2009

\section{AS TEORIAS DA REPRESENTAÇÃO E DA CLASSIFICAÇÃO}

Outro âmbito de estudos sobre a informação se desenvolve de maneira paralela às teorias anteriormente descritas e, embora inicialmente não estivesse estritamente vinculada à $\mathrm{CI}$, em pouco tempo passou a ser identificada como a área central do campo, o seu "núcleo duro", o "específico" da CI. Tal identificação se deu, sobretudo, a partir da aproximação do campo com a biblioteconomia.

Paralelamente às discussões travadas pelas teorias já vistas (a questão da eficácia do transporte físico da informação, sua função na sociedade, as contradições envolvidas com seu acesso a determinados grupos), desenvolveu-se, desde antes dos marcos tidos como fundadores da CI, todo um ramo de estudos voltados para a melhor forma de representar a informação, de classificá-la, de descrevê-la.

$\mathrm{Na}$ história da biblioteconomia, convencionou-se afirmar que o primeiro desafio da área foi o da aquisição, em períodos históricos em que os livros e registros materiais do conhecimento eram escassos e frequentemente perdidos ou intencionalmente destruídos. Ao longo dos séculos, e especialmente após o desenvolvimento da imprensa, tal desafio foi sendo cada vez mais superado, a ponto de se começar a ter coleções e acervos relativamente consistentes. A grande questão passou a ser não mais a aquisição de livros, mas sua organização, de forma a se conseguir promover a sua recuperação e o seu uso.

É ainda no século XIX que começam a surgir os primeiros sistemas de classificação bibliográfica, como o sistema de Dewey e a Classificação Decimal Universal, na esteira dos sistemas de classificação das ciências promovidas pela filosofia. A grande questão que se coloca no âmbito destes estudos é como promover a classificação do conhecimento. Não do ponto de vista filosófico, mas do ponto de vista de uma classificação "útil" - útil para a recuperação dos livros, dos itens informacionais. Não é à toa que é comum se ver a identificação de Dewey como o "Pai da Biblioteconomia" e de Otlet como o "Pai da Documentação" ou mesmo o "precursor da CI". 
Importante destacar que, também no âmbito da arquivologia, vive-se um processo semelhante: inicialmente são constituídos depósitos centrais de arquivos em várias cidades europeias (o desafio é a preservação e a aquisição) e, no século XIX, aparece o primeiro grande tratado com propostas de sistematização dos documentos arquivísticos, o chamado "Manual dos Holandeses" publicado em 1898 por Muller, Feith e Fruin.

Daí por diante, essa área de estudos assiste a uma profusão de modelos e métodos para definir as melhores formas de descrever (do ponto de vista material, relacionados a aspectos "objetivos" dos documentos) e classificar (do ponto de vista do assunto, no âmbito das bibliotecas, ou da organicidade, nos arquivos).

A fundamentação científica desse campo vai conhecer importante salto com os trabalhos do indiano Ranganathan, a partir da década de 1930, com a ideia de classificação facetada, em oposição aos modelos hierárquicos até então dominantes. A contribuição de Ranganathan desvia as discussões da problemática de sistemas específicos e suas particularidades (quantas classes de assuntos, com que notação, etc) para os fundamentos gerais dos processos classificatórios e sua lógica operacional. Suas ideias servem de inspiração para os trabalhos do Classification Research Group, da Inglaterra (FOSKETT, 1973), então já no âmbito próprio da CI, que por um lado desenvolvem diversos sistemas voltados para áreas específicas do conhecimento (domínios) e, por outro, realizam discussões teóricas sobre classificação, envolvendo problematizações acerca de linguagens e categorizações. Nas décadas seguintes, juntaram-se a esse campo as teorias do conceito, da terminologia, semântica e semiótica, entre outras. Ao mesmo tempo, instrumentos e sistemas particulares foram se desenvolvendo, como os tesauros e os instrumentos de linguagem controlada.

A partir da década de 1980, as novas tecnologias digitais somam-se a esse campo, principalmente com a ideia de hipertexto e com as diversas possibilidades de classificação da informação. Metadados, ontologias e websemântica são apenas algumas das manifestações mais recentes do encontro da pesquisa em representação e as tecnologias digitais.

O conceito de informação que emana das várias pesquisas e aplicações relaciona-se essencialmente com a ideia de representação - da possibilidade de melhorar os processos representacionais, construindo linguagens melhores, notações mais mnemônicas, classes mais consistentes, terminologias menos ambíguas. Em oposição às linguagens naturais, buscam-se linguagens controladas, em prol de uma representação que seja útil - útil para recuperar informação.

\section{P R O D U ÇÃ O E C O M U N I C A Ç Ã O CIENTÍFICA}

Logo nos primeiros anos do que se convencionou chamar de período da gênese da CI (da segunda metade da década de 1940 à década de 1960), a temática da produção científica dava a tônica das discussões sobre a informação. Tal fato levou inclusive a uma compreensão, bastante difundida, de que a CI seria, na verdade, a ciência da informação científica. Tal visão teve importantes manifestações na Inglaterra, na França, nos EUA e, também, na União Soviética.

Para a compreensão dessa teoria faz-se necessário conhecer o contexto de seu surgimento. No pósguerra, estabelece-se o fenômeno da Guerra Fria, o conflito entre EUA e URSS que se estende pelos mais variados campos, da influência política às medalhas olímpicas, da ostentação bélica à corrida espacial. Neste contexto de competição, o desenvolvimento científico e tecnológico torna-se central, estratégico. E, para o aumento da produtividade e da velocidade de produção de novos conhecimentos científicos, percebeu-se a importância da informação.

Informação passou a ser entendida, nesse contexto, como um recurso, uma condição de produtividade. Cientistas precisavam de informação com rapidez, com qualidade, com exatidão. Gastava-se tempo precioso na busca de informação, ou tinha-se desperdício de tempo na obtenção de informação

Ci. Inf., Brasília, DF, v. 38, n. 3, p.192-204, set./dez., 2009 
irrelevante ou de baixa qualidade. Mais ainda, atraso na produção por não se ter acesso à informação adequada ou relevante em determinado momento.

Diversos estudos proliferaram, nesse momento, sobre o comportamento informacional dos cientistas: de que informação eles precisam? Com que regularidade? Onde eles obtêm as informações que utilizam? Também surgiram muitos estudos sobre as diferentes fontes de informação utilizadas na ciência, as diferenças entre os vários tipos de fontes, o tempo transcorrido para a publicação de cada um dos produtos da atividade científica.

Estes estudos acabaram por desviar o foco da informação em si, enquanto produto, recurso ou documento, para os seus fluxos, a sua transferência - ou, para usar o termo mais utilizado, a sua comunicação. Surgiram vários estudos que buscavam mapear os fluxos de informação, tentando identificar quem repassava informação, quem retia, quem disseminava, quem recomendava. Vários fluxogramas foram elaborados buscando ver o "caminho" percorrido: a origem de uma informação (a partir de determinada experiência científica), sua divulgação em diferentes canais (apresentações em congressos, relatórios parciais, artigos, livros, tratados), sua disseminação por parte de diferentes agentes, sua utilização e reutilização em novas experiências e produtos, entre outros. Dois conceitos que nasceram como achados empíricos tornaram-se centrais para esse campo: o gatekeeper e os colégios invisíveis.

Na segunda metade da década de 1980, essa perspectiva de estudos, voltada para o ambiente científico e tecnológico, voltou-se para o contexto das empresas e organizações. Conservou-se o mesmo modo de raciocínio e o mesmo conceito de informação, porém adaptando-se às particularidades exigidas pelo novo universo empírico de estudos. Entre os diversos conceitos desenvolvidos na esteira dessa nova produção científica estão os novos critérios para classificação dos tipos de fontes de informação (fontes externas ou internas à organização, documentais ou informais), a importância de formas de verificação da

Ci. Inf., Brasília, DF, v. 38, n. 3, p.192-204, set./dez., 2009 confiabilidade da informação e os conceitos de conhecimento tácito e conhecimento explícito como estruturadores da noção de informação como recurso estratégico no ambiente empresarial. Daí a designação que passou a ser comum a estes estudos: gestão da informação e do conhecimento.

\section{OS ESTUDOS DE USUÁRIOS}

O campo relativo ao estudo dos usuários da informação desenvolveu-se com diferentes configurações. Os primeiros estudos, normalmente denominados "estudos de comunidade" ou de perfil de usuários, podem ser incluídos na perspectiva dos estudos funcionalistas. Seu objetivo era o de mapear características de determinada população para planejar as informações mais adequadas a serem oferecidas com fins de educação e socialização. Os estudos seguintes, denominados estudos de uso, voltados para a medição de indicadores e efetiva utilização e grau de satisfação do uso de fontes, serviços ou sistemas de informação, acabaram por consistir em estudos para a avaliação dos sistemas de informação e, nesse sentido, tinham mais o caráter de oferecimento de feedback para os sistemas. Em ambos os casos, tem-se os usuários estudados na perspectiva sistêmica. Já nas décadas de 1940 e 1950, os estudos de usuários se desenvolvem no escopo das pesquisas em comunicação científica, promovendo estudos sobre os fluxos de informação e hábitos informacionais dos cientistas. Nas décadas seguintes, extensas pesquisas quantitativas são realizadas para tentar correlacionar determinados perfis sociodemográficos dos usuários com padrões de comportamento informacional.

É apenas no final da década de 1970 que começam a surgir estudos com abordagens efetivamente voltadas para os usuários. O principal marco do desenvolvimento destes estudos é a Conferência de Copenhaguen, ocorrida em 1977, na qual vários trabalhos sugerindo tal abordagem foram apresentados e debatidos (INGWERSEN, 1992). Tais estudos se desenvolvem embasados em teorias tais como a do estado do conhecimento anômalo (Belkin), construção de sentido (Dervin), valor 
agregado (Taylor) e construtivista (Kuhlthau). Em comum, todas apresentam uma perspectiva cognitivista: busca-se entender o que é a informação do ponto de vista das estruturas mentais dos usuários que se relacionam (que necessitam, que buscam e que usam) a informação. Os usuários são estudados enquanto seres dotados de determinado "universo" de informações em suas mentes, utilizando essas informações para pautar e dirigir suas atividades cotidianas. Uma vez que se verifica uma falta, uma ausência de determinada informação, inicia-se o processo de busca de informação - aí entra a informação, como aquilo capaz de preencher uma lacuna, satisfazer uma ausência. Tal perspectiva permite compreender a informação inclusive numa lógica cumulativa, à medida que novas informações se somam às anteriores no mapa mental dos indivíduos. A principal inspiração desse modelo é a teoria de Popper, que crê na unicidade do método científico e na possibilidade de um conhecimento objetivo da realidade.

Esse modelo enfatiza as percepções dos usuários em relação à sua própria ausência de conhecimento, os passos trilhados para solucionar essa ausência (em direção à informação) e o uso da informação para a execução de determinada tarefa ou problema. No lugar das caracterizações sociodemográficas, tais estudos identificam como elemento determinante do processo as percepções dos usuários acerca de sua situação e da informação. A entrada em cena dos estudos de usuários recoloca os sujeitos em perspectiva. A informação passa a ser vista como algo na perspectiva de um sujeito.

\section{CONSOLIDAÇÃO DE UM CONCEITO}

Os primeiros conceitos de CI surgiram na década de 1960 (TAYLOR, 1966; REES; SARACEVIC, 1967; BORKO, 1968) e possuem, quase todos, a mesma ideia. Destacam que a CI é uma ciência voltada para o estudo da produção, organização, armazenamento, disseminação e uso da informação. Nesse sentido, entendem a CI como uma disciplina voltada para os processos envolvidos com a informação processos normalmente entendidos como processos técnicos, aplicados, de intervenção. O conceito de informação que sobressai de tais definições é a ideia de informação como uma "coisa", um ente da realidade dotado de objetividade.

A outra ideia muito comum nos primeiros conceitos de CI exalta o objeto de estudo dessa ciência: o "comportamento e as propriedades da informação". Tal comportamento é entendido como as direções que toma ou as conformações que adquire a partir das forças que agem sobre ela. A ideia de propriedades é entendida como propriedades objetivas, tais como, por exemplo, as propriedades físico-químicas dos elementos de uma tabela periódica - são propriedades que, uma vez descobertas, valem para quaisquer contextos, quaisquer sujeitos. À maneira de Durkheim, para quem os fatos sociais são "coisa", e de psicólogos comportamentais como Watson, que definem o comportamento como a ação objetiva, externamente observável, resultante de um estímulo igualmente objetivo, a informação é "positivada", isto é, definida enquanto algo independente dos sujeitos, dos contextos histórico-culturais, passível de ser estudada objetivamente, medida, e ser compreendida por meio de leis e regularidades.

Tal conceito é desta forma problematizado tanto na Teoria Matemática quanto na Teoria Sistêmica - ambas acabam por se complementar. A ideia de informação presente em ambas é a mesma: algo que é transportado, repassado, de um ponto a outro no primeiro caso, num esquema linear, no segundo, num processo cíclico. Nos dois casos a informação sofre a ação de processos que lhe são externos processos de emissão e recepção, no primeiro caso, e funcionais, no segundo. Juntas, as duas teorias concorrem para a construção de um verdadeiro paradigma para a área: o paradigma positivista.

As demais teorias compartilham com as duas primeiras do conceito de informação. A Teoria Crítica, embora calcada numa perspectiva epistemológica completamente diferente (a historicidade e o conflito), em relação ao conceito de informação acaba reproduzindo a mesma lógica: a informação como uma coisa, um recurso, distribuída desigualmente entre os atores, que confere, a quem a

Ci. Inf., Brasília, DF, v. 38, n. 3, p.192-204, set./dez., 2009 
tem, possibilidade maior de dominação e construção de hegemonia.

No âmbito das teorias da representação e da classificação, verifica-se a presença do mesmo conceito. À medida que se busca a construção de sistemas de representação cada vez melhores, isto é, tem-se no horizonte a perspectiva de construção de uma linguagem perfeita, sem erros, sem dubiedades, para a localização dos itens informacionais, operase numa lógica da univocidade de sentido. O que significa, na prática e mais uma vez, ignorar a presença dos sujeitos, as dimensões semântica e pragmática da informação.

Os estudos em comunicação científica corroboram as visões de informação da Teoria Matemática e da Teoria Sistêmica, apenas transportando-as para a lógica da produção do conhecimento científico. A informação é compreendida como insumo, cujo acesso e disseminação precisam ser otimizados para o ganho da produtividade. Assim também ocorre no âmbito dos estudos em gestão da informação, em que a informação é tida como insumo para a tomada de decisão de gerentes e administradores. O fluxo da informação é compreendido como um transporte físico - que, para o aumento da produtividade, precisa ser otimizado, liberado de ruídos e redundâncias.

E também os estudos de usuários de natureza cognitivista reproduziram tal conceito, com a ideia de estados anômalos de conhecimento, isto é, de lacunas na "mente" dos usuários, que seriam preenchidas com "coisas" chamadas informação, encontradas nos sistemas e serviços de informação. O mesmo princípio da univocidade presente nas teorias da classificação se repete aqui: de que a informação é algo fixo, estabelecido, com uma referência clara, direta - no caso, uma necessidade específica a ser adequadamente satisfeita.

\section{SUPERAÇÃO DE UM CONCEITO}

As tentativas mais consistentes de problematização do conceito de informação estabelecido no escopo das diferentes teorias da informação vêm tomando corpo nas duas últimas décadas, marcadas essencialmente por movimentos de reação ao paradigma positivista até então dominante, de indicações do esgotamento de seu poder explicativo.

Entre essas propostas merecem destaque as discussões que buscam estabelecer diálogo com as ciências hermenêuticas, para quem o entendimento do que a informação é passa, necessariamente, pelas interpretações dadas pelas pessoas que se relacionam com ela. Tais discussões se dão de diferentes formas. Cornelius (1996, p. 22), retomando Habermas, lembra que as ações e fatos humanos não são "dados" ao investigador do mesmo modo que os fenômenos humanos - pois são interpretados pelos sujeitos que os vivenciam ou se relacionam com eles. Se são interpretados, são dotados de sentido. E não há sentido em algum fato ou situação se não há sujeito que os experencie (1996, p. 27).

Outro autor que recorre à hermenêutica como forma de ampliar as possibilidades teóricas de estudo da informação é Capurro. O autor reconhece a existência de três "paradigmas" no campo: o primeiro, a que denomina paradigma físico; o segundo, que identifica como o paradigma cognitivo; e o terceiro, ao qual ele próprio se filia, denominado paradigma social (CAPURRO, 2003).

Criticando os dois primeiros, o autor subverte a ideia comum que se tem de que a informação é algo prévio que cria o conhecimento, propondo que, na verdade, o que ocorre é o contrário, pois a informação é o conhecimento em ação - informação é contextualizar o conhecimento, algo só pode ser considerado informação pelos atores sociais se já se tem conhecimento daquilo que é definido como informação. Capurro faz sérias críticas ao que chama de modelo representacionista (presente nos dois "paradigmas" que critica) ao recusar a ideia de representação como duplicação, na mente de um sujeito, de uma realidade externa a ele, proveniente da mente de outro sujeito. Para ele, a informação não seria, então, o produto último de um processo de representação, nem algo que é transportado de uma pessoa a outra ou mesmo algo específico para 
uma subjetividade isolada. Ela seria, antes de tudo, uma dimensão fundamental da forma como os seres humanos compartilham o mundo com os outros (CAPURRO, 1992).

Já Rendón Rojas (2005) busca ir além da tradicional distinção entre dado, informação e conhecimento, a partir de outra tríade de conceitos: informação, conhecimento e valor. $\mathrm{O}$ autor entende a informação como uma qualidade secundária de objetos particulares. Sua perspectiva é essencialmente dialética: o autor entende a informação como a união de dois extremos, os elementos objetivos (dados) e subjetivos (as estruturas interpretativas dos sujeitos). Rendón Rojas reconhece a existência de uma dimensão objetiva, mas também contempla a subjetividade dos sujeitos que vão construindo os valores (valores tais como beleza, verdade, bondade e - poderíamos acrescentar - informação). Para tal empreitada teórica, o autor mobiliza conceitos tão distintos quanto inferência, assimilação, adaptação, imaginação e criatividade.

Deve-se destacar ainda, no âmbito da CI, as aproximações junto à semiótica, com ênfase nas cadeias semiósicas, isto é, nas sucessivas elaborações e reelaborações de sentido das informações, tendo como eixo a tricotomia proposta por Peirce: objeto, signo, interpretante (SOREN, 1992). Em tais estudos, resgata-se a dimensão semântica da informação, descartada pela Teoria Matemática e por quase toda a pesquisa em CI que se seguiu nos anos posteriores à publicação das ideias de Shannon e Weaver. A informação, como signo, tem como uma de suas propriedades a vagueza própria do signo, isto é, o fato de ele representar apenas em parte algo para alguém.

Também devem ser relacionadas as teorizações contemporâneas relativas ao conceito de regime de informação, que buscam analisar os fluxos informacionais a partir de sua inserção nas dimensões político-econômicas concretas de um contexto específico, isto é, incorporando no estudo da informação os contextos institucionais, condições materiais, sistemas regulatórios e posições ocupadas pelos diferentes sujeitos que se relacionam com e para além da informação. Frohmann (2008) constrói sua fundamentação justamente a partir da crítica à abordagem cognitivista, tida por ele como uma abordagem cujo conceito de informação é essencialmente mentalista, que vê o ser humano apenas como um ser cognoscente, desprezando todos os condicionamentos sociais e materiais do existir humano. Continuando a crítica, Frohmann aponta que tal visão da informação limita o estudo dos efeitos da informação às mudanças de estado de consciência individual, e toda tentativa de estudar os efeitos públicos e sociais estaria limitada a contar quantos indivíduos são afetados. A reconstrução do conceito de informação, pelo autor, passa pela ideia de materialidade da informação conjugada com os campos institucional, tecnológico, político, econômico e cultural que configuram as características sociais da informação.

Também Braman (2004) tem trabalhado com a noção de informação articulada ao conceito de "regimes de informação", principalmente relacionada com as políticas de informação. Em tal abordagem, o papel ativo dos atores na defesa de seus interesses e na configuração dos sistemas institucionalizados ganha uma dimensão que reconfigura toda a forma de se pesquisar a informação.

Os estudos na perspectiva da análise de domínio (HJORLAND; ALBRECHTSEN, 1995) constituem importante exemplo do movimento de superação do conceito de informação, principalmente ao identificarem a existência de diferentes entendimentos do que seja informação para grupos específicos de atores que se relacionam com a informação. Ao resgatar a ideia de intersubjetividade, tais estudos apontam para o caráter construído da informação e para o papel ativo dos sujeitos que atuam no âmbito dos sistemas de informação e para além destes.

Juntos, tais estudos recuperam as dimensões material e cultural em que se dão os fluxos informacionais e representam um ressurgimento, com grande ênfase, da dimensão pragmática descartada pela Teoria Matemática: a informação existe num contexto concreto, particular, específico, que precisa

Ci. Inf., Brasília, DF, v. 38, n. 3, p.192-204, set./dez., 2009 
necessariamente ser contemplado nos estudos. Abre-se com isso, entre outras, a possibilidade de estudos com abordagens fenomenológicas - na contramão da perspectiva original da CI que ansiava por leis e generalizações sobre o "comportamento" da informação.

$\mathrm{Na}$ confluência das contribuições das teorias citadas, bem como de outras que não foram citadas neste texto, desenha-se uma perspectiva nova de estudos da informação, que a entende não mais como coisa, mas como processo - algo construído, essencialmente histórico e cultural, que só pode ser apreendido na perspectiva dos sujeitos que a produzem, a disseminam e a utilizam. A informação deixa de ser apreendida como um objeto físico, com a mesma natureza de uma cadeira, uma pedra, um elemento químico, e passa a ser entendida como um fenômeno humano (portanto, cultural e histórico) tal como o poder, a ideologia, a felicidade, entre outros.

\section{CONSIDERAÇÕES FINAIS}

A história da CI pode ser entendida, assim, como a história da gradual consolidação de um paradigma positivista para o campo, que se dá com a incorporação de teorias, conceitos e métodos de várias correntes (de diferentes áreas do conhecimento) e se manifesta de maneiras particulares nas várias subáreas que o compõem. Tal paradigma partilha com o positivismo todas as suas características: a explicação como sinônimo de simplificação, a quantificação, a busca por regularidades e leis e o consequente apagamento das singularidades. Partilha, também, suas limitações sendo a principal delas a incapacidade de capturar aquilo que o método não dá conta de apreender: a informação subjetiva, dotada de sentidos diversos e inserida no terreno da experiência histórico-cultural.
Ao longo de sua própria evolução, contudo, principalmente nas duas últimas décadas, reflexões teóricas, discussões consistentes sobre o próprio conceito de informação e achados empíricos das pesquisas realizadas têm colocado em xeque a hegemonia desse modelo - ainda que outro modelo ou teoria geral não tenha, ainda, emergido. Provavelmente, aliás, tal modelo sequer venha a emergir, pois o tipo de crítica apontada nos vários estudos contemporâneos se dá mais numa perspectiva pontual, em relação a um ou outro aspecto, do que de uma forma geral, global.

O que a existência de tais estudos evidencia é a complexidade do fenômeno estudado - a informação - e a consequente complexidade necessária para as teorias que se propõem a estudálo. Assim, o movimento de superação teórica da CI tende a ser o movimento da incorporação da complexidade, por um lado; e da sua vinculação decisiva ao terreno das ciências humanas e sociais, de outro.

Deve-se salientar, contudo, que estudos de natureza positivista, que reafirmam o conceito de informação na perspectiva objetivista, sem a consideração do sujeito e dos contextos socioculturais concretos, que tomam a informação como um dado e não como uma construção, continuam existindo e constituindo a perspectiva mais comum dos estudos desenvolvidos no campo. Ou seja: a consciência da imaturidade do campo existe (WERSIG, 1993), e o que se percebe é que ainda existe longo caminho a trilhar rumo à maior consistência - principalmente em relação à consolidação das críticas que têm sido feitas ao modelo positivista de compreensão da informação e à possibilidade de construção de novas teorias e conceitos.

Artigo submetido em 30/04/2009 e aceito em 22/04/2010. 


\section{REFERÊNCIAS}

BRAMAN, Sandra. The emergent global information policy regime. Houndsmills: Palgrave Macmillan, 2004, p. 12-37.

BORKO, H. Information science: what is this? American Documentation, v. 19, 3-5, 1968.

BOURDIEU, Pierre. $A$ distinção: crítica social do julgamento. Porto Alegre: Zouk; São Paulo: Edusp, 2007.

BUCKLAND, M. K. Information as a thing. Journal of the American Society for Information Science, v. 42, n. 5, p. 351-360, Jun. 1991.

CAPURRO, Rafael. What is information science for? A philosophical reflection. In: VAKKARI, P.; CRONIN, B. (Eds).Conceptions of library and information science: historical, empirical and theoretical perspectives. Londres; Los Angeles: Taylor Graham, 1992. p. 82-96.

CAPURRO, Rafael. Epistemologia e ciência da informação. In: ENCONTRO NACIONAL DE PESQUISA EM CIÊNCIA DA INFORMAÇÃO, 5., 2003, Belo Horizonte. Anais... Belo Horizonte: Associação Nacional de Pesquisa e Pós-Graduação em Ciência da Informação e Biblioteconomia, 2003. 1 CD-ROM.

CORNELIUS, Ian. Meaning and method in information studies. New Jersey: Ablex, 1996.

FOSKETT, A.C. A abordagem temática da informação. São Paulo: Polígono; Brasília: Ed. UnB, 1973.

FROHMANN, Bernd. O caráter social, material e público da informação. In: FUJITA, M.; MARTELETO, R.; LARA, M. (Orgs). A dimensão epistemológica da ciência da informação e suas interfaces técnicas, políticas e institucionais nos processos de produção, acesso e disseminação da informação. São Paulo: Cultura Acadêmica; Marília: Fundepe, 2008, p. 19-34.

HJORLAND, Birger; ALBRECHTSEN, Hanne. Toward A New Horizon in Information Science: Domain Analysis. Journal of the American Society for Information Science, v. 46, n. 6, p. 400-425, 1995.

INGWERSEN, Peter. Conceptions of information science. In: VAKKARI, P.; CRONIN, B. (Eds). Conceptions of library and information science: historical, empirical and theoretical perspectives. Londres; Los Angeles: Taylor Graham, 1992, p. 299-312.
LE COADIC, Yves. A matemática da informação. In: TOUTAIN, Lídia (Org). Para entender a ciência da informação. Salvador: Edufba, 2007, p. 219-238.

MATTELART, Armand. História da sociedade da informação. São Paulo: Loyola, 2002.

RANGANATHAN, S.R. The five laws of library science. Madras: Madras Library Association; London: Edward Goldston, 1931.

REES, Alan; SARACEVIC, Tefko. Education for information science and its relation to librarianship. [não publicado]. 1967.

RENDÓN ROJAS, Miguel Ángel. Relación entre los conceptos: información, conocimiento y valor. Semejanzas y diferencias. Ciência da Informação, Brasília, v. 34, n. 2, p. 52-61, maio/ago. 2005.

RIVIÈRE, Georges. La museología: curso de museología, textos y testimonios. Madrid: Akal, 1993.

SARACEVIC, Tefko. Ciência da informação: origem, evolução e relações. Perspectivas em Ciência da Informação. Belo Horizonte, v. 1, n. 1, p. 41-62, jan./jun. 1996.

SCHELLENBERG, T.R. Arquivos modernos. Rio de Janeiro: FGV, 1973.

SHERA, Jesse. Sociological foundations of librarianship. New York: Asia Publishing House, 1970.

SOREN, Brier. A philosophy of science perspective - on the idea of a unifying information science. In: In: VAKKARI, P.; CRONIN, B. (Eds). Conceptions of library and information science: historical, empirical and theoretical perspectives. Londres, Los Angeles: Taylor Graham, 1992, p. 97-108.

TAYLOR, R.S. Professional aspects of information science and technology. In: CUADRA, C.A. (Ed). Annual Review of Information Science and Technology. New York: John Wiley, v. 1, 1966, p. 15-40.

WERSIG, Gernot. Information science: the study of postmodern knowledge usage. Information Processing \& Management, v. 29, n. 2, Mar. 1993, p. 229-239. 